\title{
Distopias presentes, passadas e futuras: os monstros da sociedade
}

\author{
CLAEYS, Gregory. Dystopia: A Natural History. A study of \\ modern despotism, its antecedents, and its literary diffractions. \\ Oxford: Oxford University Press, 2017, 556 p.
}

\section{Vittorio da Gamma Talone*}

\section{Resumo}

A presente resenha abarca a obra de Gregory Claeys mapeando o que chama de história natural da distopia, cujo objetivo é dar conta da passagem, na sociedade, dos medos naturais (deuses, monstros) para os medos sociais (tecnologias opressivas, totalitarismo). Analisarei como o autor busca, atentando a fatos históricos, mitos, religiões, sistemas políticos e à chamada "literatura distópica", dar conta da dimensão comportamental-emocional e das sensações definidoras de distopias para diferentes grupos e sociedades. Com isso, serão observados não apenas cenários e obras projetadas como distópicas, mas contextos passados e presentes assim caracterizados: a tarefa é justamente alertar e educar sobre as distopias da vida real. Considerando a presente conjuntura político-socioeconômica, é um esforço que intenta forçar a conceber soluções coletivas em momentos de crescente irracionalidade e pânico.

Palavras-chave: Distopia, Utopia, Totalitarismo, Terror, Literatura.

*Instituto de Estudos Sociais e Políticos da Universidade do Estado do Rio de Janeiro, Rio de Janeiro, RJ, Brasil 


\section{Present, past \& future dystopias: the monsters of society}

\section{Abstract}

The present review looks into the work of Gregory Claeys that maps what he calls the natural history of dystopia, aiming to account for the passage, in society, from natural fears (gods, monsters) to social fears (oppressive technologies, totalitarianism). I will analyze how the author seeks, by examining historical facts, myths, religions, political systems and the so-called "dystopic literature", to deal with the behavioralemotional dimension and the sensations that define dystopias for different groups and societies. Thereby, not only scenarios and works projected as dystopic are considered, but also past and present contexts so characterized: the task is precisely to alert and educate about the real-life dystopias. Considering the present politicalsocioeconomic context, it is an effort that intends to induce envisioning collective solutions in moments of growing irrationality and panic.

Keywords: Dystopia, Utopia, Totalitarianism, Terror, Literature

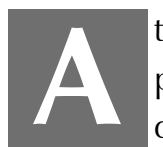

tentando a variadas dimensões da vida social hodiernamente, percebem-se situações/contextos/realidades em que a existência de pessoas ou grupos está diretamente ameaçada: o Brasil está na décima posição no ranking mundial quanto à taxa de homicídios, de acordo com dados da Organização Mundial da Saúde (OMS), os quais atingem sobretudo homens jovens negros - um morto a cada 23 minutos ${ }^{1}$. Donald Trump, empresário norte-americano e presidente da maior potência bélica mundial, provocou um dos maiores riscos de guerra nuclear das últimas décadas por "trocas de farpas" com o ditador Kim Jong-un, da Coreia do Norte. Anos de guerra na Síria, com participação de diferentes países, contra o grupo terrorista Estado Islâmico, cuja atuação provocou milhares de mortes, geraram uma conjuntura de calamidade no país - em seis anos de conflito, o número de refugiados sírios supera os 5 milhões. Esses são apenas alguns poucos exemplos atuais que, há anos atrás, poderiam

1 Segundo dados da Comissão Parlamentar de Inquérito do Senado sobre o Assassinato de Jovens. O que pode ser consultado no seguinte link: https:/www12.senado.leg.br/noticias/ arquivos/2016/06/08/veja-a-integra-do-relatorio-da-cpi-do-assassinato-de-jovens (acesso em 30 jan 2018). 
ser lidos como parte de um futuro distópico: um porvir em que a vida de diversos grupos ou povos estaria diariamente afetada e colocada em risco.

Como destaca Gregory Claeys, autor do livro aqui resenhado, "a palavra [distopia] é derivada de duas palavras gregas, dus e topos, significando um lugar doente, ruim, defeituoso ou desfavorável"2 (p. 4). Normalmente, conceberíamos a distopia pensando apenas a partir da literatura ou da cinematografia, mas "[existem] usos não literários e empíricos do termo" (p. 5). Aqui encontra-se o dado primordial e a característica mais relevante do livro: distopias podem não só existir nesse exato momento, como formaram a realidade de diferentes grupos ao longo da história.

Claeys, professor de História do Pensamento Político na Universidade de Londres, publicou reconhecidos livros/artigos sobre, por exemplo, a ideia de utopia (tendo sido premiado por seu trabalho), a respeito da Revolução Francesa e do Socialismo. A partir de seus estudos, logo na Introdução, o autor indica existirem distintas formas de distopia. O fio condutor seria pensar um lugar (mundo, país, estado, região, continente etc.) ruim para determinado grupo, no sentido de este estar invariavelmente ameaçado, caçado, proibido, oprimido, culminando em possibilidades correntes de morte/extermínio, sendo a tônica o medo e a desconfiança - para Cleys, algo normalmente provocado por um regime político.

A partir dessas considerações, avança-se na Parte I do livro, envolvendo a própria Introdução e capítulos que exploram as origens da ideia de distopia. A Parte II é voltada a pensar a relação de distopia com diferentes totalitarismos, examinando desde as consequências da Revolução Francesa aos Gulags bolcheviques. Por fim, na Parte III, o autor dá atenção à literatura distópica e como essa, em sua opinião, destaca-se contra o coletivismo considerado um fator criador de distopias (reais, inclusive) e alvo crítico de diversas obras -, abordando desde sátiras do século XIX às distopias apocalípticas do século XXI. Todos os exemplos são assentados na realidade europeia, afirma o autor.

${ }^{2} \mathrm{O}$ livro possui publicação apenas em inglês. Portanto, as citações traduzidas neste texto são de minha autoria. 
Claeys, ao longo do livro, sugere pensarmos a distopia como um estado psicológico, levando-nos a concebê-la como o ponto de partida da humanidade. Em termos de "história natural", vemos a passagem de medos naturais (deuses, monstros) para medos sociais (tecnologias opressivas, totalitarismo): "o medo permanece constante, flutuando, mesmo se seus objetos variam" (p. 9). Para dar conta do primeiro momento, elegem-se obras de antropologia, analisando as sociedades descritas por Lucien Lévy-Bruhl, Bronislaw Malinowski e Sigmund Freud: seríamos sempre e persistentemente desafiados por ameaças de morte, lesões, doenças e aflições. Sociedades inteiras seriam protótipos distópicos de paranoia e agressão.

Avançando aos coletivismos modernos, evidencia-se como a escravidão, despotismos políticos e prisões prosseguiram a lógica. Aqui a distopia estaria intimamente entrelaçada com discursos sobre "crise" e "inimigos" conjugados à necessidade de submissão de outros por algum meio. A ideia do inimigo é importante, pois um grupo desloca suas ansiedades incorporando seus medos em outros - produzindo uma distopia para estes. Logo, ainda que conservemos medos naturais, progressivamente assumimos aqueles formulados socialmente.

Levando em conta esses pontos, Claeys dedica tópicos, ainda na Parte I, a uma longa discussão conceitual a respeito da Psicologia de grupo e sua relação com a distopia. A partir dos exemplos dados, sua intenção é pensar como medos coletivos e o ódio, por exemplo, geralmente são expressos, experimentados e definidos por grupos. Com isso, mobilizam-se os conceitos de multidão por Gustave Le Bon (1896), público de Gabriel Tarde (2010), e grupo de Sigmund Freud (1960). A intenção de mostrar como os indivíduos se relacionam com grupos visa entender como a tensão entre o coletivismo e o individualismo se desenvolve no período moderno, vindo a definir o distópico. Mas esse movimento pode não ser claro ao leitor, pois parece faltar aderência da análise com a própria definição inicial de distopia - nesse momento, ela parece ser tomada como qualquer realidade ou fato que simplesmente envolva medo e/ou morte. A ideia de coletivismo distópico começa a tomar forma, mas falta uma definição clara, destacada, 
e referência empírica ao conceito. Isso pode ser decorrência da própria estrutura da Parte I, em que só após toda esta discussão é apresentada uma sessão nomeada "O argumento do livro" - que poderia iniciar a obra.

Os capítulos seguintes visam retomar os "monstros" dos seres humanos presentes desde o início dos tempos. Monstros habitariam a terra incógnita primordial do Mundo, marcariam o início da história natural da distopia. Teriam a ver com o medo da morte para as mais diversas sociedades. Aqui Claeys aborda desde o homem selvagem, vampiros e lobisomens, à reinvenção moderna da monstruosidade com o período do "Esclarecimento", em que se tornaram pessoas, como o Frankenstein, de Mary Shelley. Obviamente temos também o inferno e Satanás: uma matriz para o conceito posterior de distopia. Sua existência teria papel em bodes expiatórios representados por uma variedade de grupos na Europa cristã: judeus, hereges e mulheres consideradas como bruxas ${ }^{3}$. Processo que gerou uma realidade distópica para esses grupos. Destaca-se, também, a Inquisição, tendo ela caracterizado um cotidiano - a partir da ideia de heresia - de suspeitas mútuas, mais angustiante do que o imaginado por George Orwell em 1984, em que a morte se tornou um destino comum. Ela teria sido operada para reforçar o poder de um grupo dominante durante séculos e excluir e reprimir mulheres, hereges, judeus e "desviantes" de muitos tipos.

Avançando à Parte II, Claeys analisará até que ponto essa mentalidade permeou regimes totalitários do século XX. As "distopias" são identificadas nos campos de concentração e prisões da Alemanha e da União Soviética, segundo o autor, sendo o Estado socialista e Josef Stalin seus grandes focos. Nem a narrativa histórica nem a expressão literária conseguiriam capturar a gravidade desses eventos. Assim, Claeys almeja dar voz às vítimas de tais regimes o quanto possível, mais do que analisar livros - os relatos nos informariam "mais diretamente como a distopia funciona e, tão importante quanto, como [ela é sentida]" (p. 114).

${ }^{3}$ A misoginia presente no cristianismo gerou "Uma vida assombrada pelo medo do pecado e dominada pelo terror [definindo uma] psicologia da distopia" (p. 95). 
Ponderando desde a Revolução Francesa, destaca-se a relação de utopia com distopia, indicando como esta pode tomar forma a partir de um ideal de revolução, antes tido como libertador. O momento tomado pelo autor, por exemplo, normalmente é creditado como virada à modernidade, que busca incorporar desejos de liberdade e igualdade, erradicar o antigo para construir o novo. Mas também se manifestaram xenofobia, exclusão, liberdades sendo suprimidas e violências: tais pontos seriam caracterizadores de uma distopia.

Análise semelhante é feita com a Revolução Russa. Esta seria uma referência de liberdade contra o despotismo e uma extensão das lutas americanas e francesas por liberdade. $\mathrm{O}$ que logo teria dado lugar a barbarismo, brutalidade, perseguição, tortura e morte de inimigos. Destacase como o medo e a falta de confiança teriam sido os principais fatores de vida na União Soviética: emoções que substancializam a distopia.

Em mais uma experiência europeia do século XX contendo características distópicas, o autor chega ao Nazismo: utopia para a Alemanha - em busca de um purismo racial - e distopia para todos os outros. "Inferno", destaca Claeys, seria a analogia mais próxima ou construção imaginária que teríamos de Auschwitz: a maioria dos relatos em relação ao local nomeava-o "inferno na terra". A violência permeava tudo, terror e medo universal eram regra para as vítimas e perseguidos dos nazistas - principalmente judeus. A morte poderia vir repentinamente por espancamento, fuzilamento, afogamento, soterramento vivo e outras formas de homicídio. A própria "Tropa de Proteção" (SS), grupo paramilitar do partido nazista, possuía características do antes definido como grupo distópico, construindo sua identidade sobre o ódio e a opressão implacável contra os inimigos. Se o inferno para os cristãos tinha uma função - pelos bons atos e arrependimento, ter-se-ia o perdão -, o campo de concentração era uma forma de desumanizar cujo fim era puramente a morte.

A Revolução Francesa, a Revolução Russa e o Nazismo são comparados e analisados pelo autor, guardadas as devidas proporções, no sentido de busca de um lugar perfeito levando a um contexto de perseguição de 
grupos, terror e morte em grandes números. De acordo com o autor, não se teria dado verdadeira atenção à gravidade desses regimes, justificando assim suas escolhas ${ }^{4}$.

Na sequência da Parte II, foca-se na China do século XX, no Camboja de Pol Pot e há ainda um pequeno subtópico sobre a Coreia do Norte. Assim, Clayes prossegue tratando de forma aberta o conceito de "totalitarismo" durante toda esta parte, acabando por pensar mais em como uma distopia pode ser formada - por aqueles que a constroem - do que em como se sentem as pessoas submetidas a ela - que justamente indicariam a realidade de uma distopia -, algo antes indicado como eixo do livro.

Concluindo a Parte II, argumenta Claeys:

Indubitavelmente, a compreensão desses fenômenos extraordinariamente complexos não pode ser confiada com segurança ao historiador ou ao sociólogo sozinho. A literatura distópica emergiu como uma das correntes intelectuais mais poderosas do nosso tempo. Como os seus insights podem variar, complementar ou ficar aquém da história que examinamos até agora, devemos considerá-la (p. 268).

Adentremos na Parte III. Claeys, inicialmente, justifica refletirmos sobre as questões aqui levantadas, por meio da literatura. Esta conseguiria comunicar experiências a níveis individuais/emocionais que podem ser perdidas no "anonimato" da narrativa histórica. Acompanhar personagens dentro do contexto dá mais gravidade ao evento distópico - falar em milhões pode traduzir-se em estatística, pensar em "massa" nos faria perder a dimensão imediata/urgente do terror. As distopias literárias normalmente são futuros imaginários em que alguma coisa deu muito errado na sociedade, retratando rebeliões por indivíduos e grupos contra o coletivismo e simbolizando valores com os quais o leitor deve simpatizar. Tais obras se deram em

4 Todos os acontecimentos considerados teriam um grupo focado em raça, gênero ou classe para articular um bode expiatório de "outros" (monstros, bruxas, e Diabo) que, desumanizados, vieram simplesmente a simbolizar o mal; além de um ideal de futuro (o Reich milenar, a abolição do estado), como salvação religiosa, pelo qual sacrifícios são cometidos e justificados. 
um momento (movimentos revolucionários culminando em despotismos, desenvolvimento da ciência podendo auxiliar a vida social ou exterminar uma população), argumenta Claeys, em que a civilização foi vista como capaz de degeneração tanto quanto de progresso. A tarefa da literatura distópica é imaginar esses futuros diretos e sugerir alternativas.

As distopias destacadas por Claeys como primeiras datam do período revolucionário francês (capítulo 5). Mas o gênero literário começaria apenas na década de 1870, obtendo grandes sucessos no início dos anos 1930. Como destacado nos capítulos 6 e 7, têm-se os marcos de Aldous Huxley e George Orwell em meados do século XX. No capítulo final, são explorados os desenvolvimentos da década de 1950 até o presente (2015) por obras cintilantes. Claeys destaca: "[assim] como a utopia, um aspecto-chave do contexto da distopia é o seu retrato das relações sociais e políticas" (p. 270).

No capítulo 5, buscando as origens da literatura distópica, o autor volta-se novamente à análise do próprio termo:

O termo 'distopia' foi evidentemente cunhado em 1747, escrito como 'dustopia'. Em 1748, a 'distopia' foi definida como 'um país infeliz' [por Budakov]. O uso relevante seguinte veio em um discurso de 1868, de John Stuart Mill, no Parlamento. Ali chamou a política britânica na Irlanda de 'muito ruim para ser praticável', e seus defensores como 'cacotopianos' (como no grego, lugar ruim), ou dis-topianos. [...] A distopia veio a uso comum significativo no final do século XX e, principalmente, na literatura secundária, concentrando-se em textos contemporâneos" (p. 274).

No entanto, as distopias não são redutíveis a uma história das ideias como Karl Mannheim (1968) procede com a Sociologia do Conhecimento para pensar a utopia -, pois suas narrativas e elementos variam em excesso. A literatura distópica possuiria como substância a densidade narrativa sociopolítica e a relação plausível/íntima com o período em que foi escrita, retratando sociedades em que a maioria substancial sofre escravidão/ opressão "como resultado da ação humana" (p. 290), principalmente de grupos privilegiados beneficiando-se disso. Nas palavras de Claeys: 
Nascida da sátira, a distopia literária assumiu a sua primeira forma moderna após a Revolução Francesa. Surgiu como gênero consolidado nos Estados Unidos e na Grã-Bretanha, nas últimas décadas do século XIX, alimentado pela industrialização, crescente desigualdade social e crescente popularidade do socialismo e do darwinismo social. A distopia desafiava o estado de espírito da época, ao afirmar que tanto a evolução como o retrocesso podem definir a modernidade" (p. 355).

Após examinar o período inicial, Claeys foca no período entre as duas guerras mundiais, cujos textos possuiriam um foco anti-bolchevique e anti-fascista. O principal destaque é a obra destacando uma revolução russa que sucumbiu por adotar meios violentos e a escravidão em massa como um custo legítimo para alcançar sua utopia, consistindo em uma sátira da mentalidade coletivista: trata-se de We, de Yevgeny Zamyatin, distinguida por Claeys como uma das mais bem-sucedidas distopias do início do século XX.

Após a Grande Guerra, o tom satírico teria ficado mais raro devido aos "pesadelos" muito mais realistas do período. Assim, em meados do século XX, duas obras viriam a definir a resposta literária distópica ao nazismo e totalitarismos: Admirável Mundo Novo (1932) de Huxley e 1984 (1949) de Orwell. Ambos lidam com a problemática da ditadura política e a natureza sobrepujante da civilização-da-máquina. Nos subcapítulos seguintes, o autor aborda a vida de Huxley e Orwell - assemelhando-se ao tratamento dado por Norbert Elias (1995) a Mozart, obviamente em um grau menos apurado de análise sociológica -, destacando o contexto em que viveram e cresceram, de exploração imperialista europeia e norteamericana, resultando nas Guerras Mundiais. Admirável Mundo Novo seria uma extensão da sugestão darwiniana de que a ciência poderia assumir o controle sobre a evolução humana e produzir o domínio das espécies, mas seguindo-se do pesadelo humano de guerra global e colapso econômico.

Em 1984, o vocabulário "orwelliano" seria a tradução de como pensamos o totalitarismo e formas de estado de vigilância. Claeys escreve sobre a pungência da obra: 
Anthony Burgess denominou 1984 'uma das poucas visões distópicas a ter mudado os hábitos de pensamento dos homens'. Orwell já foi chamado de 'o escritor político mais influente do século $X X^{\prime}$ '. O poder deste livro reside em sua capacidade de atrair o leitor para um mundo definido pela paranoia, opressão, medo e dor (p. 391).

O tema central de 1984 é a fragilidade da memória: o Partido - grupo, antes revolucionário, que governa apenas pelo poder e para manter o poder, sendo uma crítica à condução da União Soviética por Stalin - reescreve constantemente o passado para que nenhum ponto de comparação revele se a vida já foi melhor ou pior. Não se sabe se ela é ruim/degradante, pois não há meios de compará-la com nada. Gregory Claeys ressalta a importância do livro: "[o] que Orwell descreveu em 1984 não só aconteceu, [mas] ocorreu em grande escala e com uma profundidade psicológica muito intensa e, portanto, muito mais assustadora - por ser real - do que no romance" (p. 446). Estudamos e destacamos as distopias justamente porque elas exploram e exibem detalhadamente contextos de desgraças envolvendo diversos grupos, cujas vidas estão em risco.

Finalmente, chegando ao capítulo 8, pensa-se a distopia pós-totalitária do período 1950-2015. Claeys opta por descrever inúmeras obras passíveis de serem encaixadas no gênero literário, ligando-as a regimes políticos. É um exercício de fôlego, mas que acaba perdendo o foco proposto de observação de distopias, o fio condutor. Muitas vezes, o leitor se depara com descrições de livros, mais ou menos extensas, chegando à sua classificação como distopia coletivista, distopia totalitarista etc.

O próprio autor reconhece a dificuldade de efetivar sua proposta, considerando os diferentes temas e os múltiplos elementos que remodelaram a escrita distópica nesse último período considerado. Sobressaem cinco principais temas: 1) na década de 1950, a humanidade introduzida à era nuclear, deixada próxima à destruição em escalas nunca antes previstas; 2) a partir da década de 1970, tem-se a degeneração ambiental, por vezes associada às mudanças climáticas, prevendo cenários catastróficos; 3) concomitantemente, tem-se o progresso da mecanização, provocando 
paulatinamente a subordinação de pessoas a máquinas, e distorcendo a identidade humana e a relação humano/máquina; 4) avançando à década de 1980, depara-se com as sociedades liberais, provocando degeneração cultural e social associada a um ethos de consumo hedonista; 5) por fim, nas últimas duas décadas, a atenção volta-se aos terrorismos e à Guerra ao terror. Com tantas distopias, torna-se penoso analisá-las ou classificá-las, principalmente por não ter decorrido tempo suficiente para ponderar sobre os textos produzidos ou pensar o período densamente - argumenta o próprio autor. Portanto, opto aqui por destacar uma obra de cada década, focando naquelas que parecem ser as mais exemplares a Claeys, como Walden II (1948) de Burrhus F. Skinner, que trata de uma sociedade utópica, mas cujos humanos são tratados como ratos em um laboratório, estando a liberdade de expressão e o pensamento limitados. Na década de 1950, tem-se a "distopia tecnológica" Player piano (1952), de Kurt Vonnegut, situada num pós-terceira guerra, em que máquinas de propriedade de grandes empresas fazem a maior parte do trabalho "de humanos para humanos", mas apenas uma elite de gerentes, cientistas e engenheiros se beneficiam delas - trata-se de uma sátira sobre a vida corporativa ${ }^{5}$. Na década de 1960, destaca-se $A$ Laranja mecânica (1962) de Anthony Burgess, que projeta uma ruptura da ordem social num futuro próximo, abarcando a violência gratuita de gangues e uma terapia da aversão, trazendo a questão do controle das escolhas pelos indivíduos ${ }^{6}$. Na década seguinte, The Lathe of heaven (1971) de Ursula Le Guin, situa-se numa realidade de problemas ambientais causados por superpopulação, aquecimento global, epidemias e ondas de crime, ainda projetando a escassez de alimentos e abundância de guerras no Oriente Médio.

Na década de 1980, destaca-se uma das mais realistas e influentes entre escritores distópicos contemporâneos - nas palavras do próprio Claeys: a canadense Margaret Atwood. Seu livro, The Handmaid's tale

${ }^{5}$ Um tema destacado como crescente por Claeys.

${ }^{6}$ Claeys recupera a fala de Burgess descrevendo o livro, em 1972, "como um 'sermão ... sobre a importância do poder de escolha' cujo principal objetivo era 'declarar que é preferível ter um mundo de violência levado a cabo em plena consciência - violência escolhida como um ato de vontade - do que um mundo condicionado a ser bom ou inofensivo'" (p. 462). 
(1986), retrata uma ditadura fundamentalista cristã, em que mulheres uniformizadas nascidas como escravas existem apenas para atenderem às necessidades da elite que governa a República retratada na obra - seu principal ponto é a desumanização da essência da vida das mulheres tidas como servas na história. Nos anos 1990, destaca-se a distopia corporativa presente no volumosíssimo Graça infinita (1996), de David Foster Wallace, ambientado em um futuro superestado americano em que as empresas são tão poderosas que nomeiam anos com bases em seus produtos - a história situa-se no Ano da Fralda Geriátrica. Por fim, nos anos 2000 surgem variadas obras pós-apocalípticas, como a de Cormac McCarthy, The Road (2006): aqui acompanha-se as viagens de um homem e seu filho em um cenário sombrio e violado, após um desastre não especificado que matou a maior parte da população. Como muitos livros recentes pensando distopias, o totalitarismo corporativista é o centro da realidade descrita.

Portanto, a história natural da distopia começa com um "apocalipse metafórico" - um deus irritado castiga a maldade da humanidade com uma inundação - e termina, parece a Claeys, com várias distopias reais criadas pela agressão da humanidade contra si e contra a natureza. A distopia teria funcionado para projetar variantes sobre o destino da humanidade, ela "descreve os passados e lugares negativos que rejeitamos tão profundamente por serem desumanos e opressivos, e projeta futuros negativos que não queremos, mas que podem ser obtidos de qualquer maneira [...]. A distopia define, cada vez mais, o espírito do nosso tempo" (p. 498). Logo, os "pesadelos" mencionados ao longo do livro indicam uma centralidade vigente da distopia. Como coloca o autor:

A literatura distópica pode ter ficado aquém, diante de tanto horror, ao descrever os genocídios do século XX. Mas agora, particularmente onde a ciência e a tecnologia são centrais, suas projeções têm muito a oferecer. $\mathrm{O}$ novo, que nos avisa, nem sempre é melhor. 'Progresso' não é automático e pode ser perigoso. O que beneficia poucos pode prejudicar muitos. As máquinas podem nos devorar. Assim como corporações ou revolucionários. Indo em direção à incerteza, mas claramente um futuro perigoso, precisamos de visões de alternativas - mesmo de utopias - para delinear quais caminhos 
sugerem os maiores e quais os menores males. Precisamos da visão de longo prazo, não do curto-prazismo que a política e o desejo por gratificações cada-vez-mais-imediatas nos impõem. A tarefa da distopia literária, então, é alertar-nos e educar-nos sobre as distopias da vida real. Não precisa fornecer um final feliz para fazê-lo: o pessimismo tem seu lugar. Mas pode conceber soluções racionais e coletivas, lá onde florescem a irracionalidade e o pânico. O entretenimento desempenha um papel neste processo. Mas a tarefa em questão é séria. Ganha importância diariamente. Aqui, então, está um gênero e um conceito cuja hora chegou. Que ele floresça" (p. 501).

Portanto, o esforço empreendido por Claeys é hoje de extrema relevância: relembrar o passado - as distopias escritas por pessoas que o vivenciaram, visando entender e atentar ao presente (nossos e dos outros, para que não se gere uma distopia à alteridade) - é essencial ao futuro sendo construído - algo que nunca seria possível na realidade descrita por Orwell em 1984. Exercitar a memória e as projeções de futuros possíveis pode auxiliar o delineamento corrente de caminhos à sociedade em que se torne cada vez mais difícil de reproduzir desgraças aos outros.

Vittorio da Gamma Talone é Doutorando pelo Instituto de Estudos Sociais e Políticos da Universidade do Estado do Rio de Janeiro (IESP-UERJ).

$\equiv$ vittorio.talone@gmail.com

\section{Referências}

1. ELIAS, Norbert. Mozart, sociologia de um gênio. Rio de Janeiro: Zahar, 1995.

2. FREUD, Sigmund. Group psychology and the analysis of the ego. Nova York: Bantam Books, 1960.

3. LE BON, Gustave. The crowd: a study of the popular mind. Londres: T. Fisher Unwin, 1896.

4. MANNHEIM, Karl. Ideologia e utopia. Rio de Janeiro: Zahar Editores, 1968.

5. TARDE, Gabriel. On communication and social influence. Chicago: University of Chicago Press, 2010.

Recebido: 09 fev. 2018

Aceito: 30 maio 2018 